\title{
Erratum
}

\section{Risks from GMOs due to Horizontal Gene Transfer}

\section{Paul KEESE*}

Office of the Gene Technology Regulator, GPO Box 9848 Canberra, ACT 2601, Australia

Received December 6, 2007; accepted May 16, 2008.

Published - (c) INRA, EDP Sciences, 2008.

The address of the author of the article Keese P (2008) Risks from GMOs due to Horizontal Gene Transfer. Environ. Biosafety Res. 7: 123-149 has changed recently. Therefore the correct address is:

Office of the Gene Technology Regulator, GPO Box 9848 Canberra, ACT 2601, Australia.

* Corresponding author: paul.keese@health.gov.au 